\title{
KNOWLEDGE, ATTITUDE \& PRACTICE OF COVID-19 AMONG HEALTH CARE WORKERS OF TERTIARY CARE HOSPITAL IN SOUTHERN RAJASTHAN
}

\section{Dr C.P.Sharma}

\section{Dr Anum Fatima*}

Dr Omprakash Mahawar

\section{Pratap Bhan} Kaushik
Assistant Professor, Dept of Community Medicine RNT Medical College, Udaipur

Resident Doctor,Dept of Community Medicine RNT Medical College, Udaipur * Corresponding Author

Resident Doctor,Dept of Community Medicine RNT Medical College, Udaipur

Lecturer in Statistics, Dept of Community Medicine RNT Medical College, Udaipur

ABSTRACT

BACKGROUND: The COVID-19 pandemic is escalating at an alarming rate and currently best therapy lies in prevention. OBJECTIVE:This study aims to determine knowledge, attitude and practice of health care workers towards COVID-19.METHODOLOGY:A cross sectional descriptive study undertaken at Dedicated Covid Hospital, MBGH Udaipur,Rajasthan from April 2020 to May 2020.The response of 190 participants who filled questionnaire was tabulated and analysed .RESULT :Majority had an average knowledge (49.7\%),positive attitude (57.4\%) and good practice(51.1\%) which was further influenced by various factors studied. CONCLUSION :Health care workers still require professional education and teachings dedicated to improve knowledge and promote good attitude and practice in regards of COVID-19.

\section{KEYWORDS : COVID-19, Knowledge, Attitude, Practice, Health care worker}

\section{INTRODUCTION:}

The novel coronavirus is presently the most talked about disease which has lead to the worldwide Coronavirus disease-2019 outbreak i.e. COVID-19.Virus is known to be transmitted through birds and mammals, with humans being particularly susceptible to its infection and transmission. ${ }^{1}$ It was first reported by Chinese authorities in Wuhan city, the capital of Hubei province in China at the end of December $2019^{2}$. It was declared as a pandemic on 11 March 2020 by WHO.In India, the first case was reported on 30 January 2020 from the state of Kerala.The emergence of this infectious disease has caused much anxiety within the population due to escalating number of suspected cases and the virus'

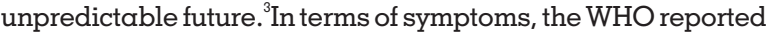
that more than $80 \%$ of COVID-19 patients showed mild symptoms and recovered without any medical intervention, approximately $20 \%$ of infected cases had a severe illness such as shortness of breath, septic shock and multi-organ failure, and it has been reported that an estimated $2 \%$ of cases can be fatal $^{1}$. The best prevention is to avoid being exposed to COVID-19. This is done by washing hands with soap and water, and using face masks, isolating confirmed and suspected cases.

Health care workers (HCWs) are at the front line of the COVID-19 outbreak response. Theyare at a high risk of infection and can also act as source of transmission in the community. They face hazards like pathogen exposure, long working hours, psychological distress, fatigue, occupational burnout, stigma, and physical and psychological violence. ${ }^{5}$

\section{METHODOLOGY:}

- Study Design and Site:Across-sectional, descriptive study was undertaken between April 2020 and May 2020 through a self designed questionnaire among HCWs of a District Hospital in Southern Rajasthan.The questionnaire comprised of 16 questions related to knowledge and 5 questions related to attitude and practice each.

- Study Population:The HCWs including doctors,interns, pharmacists, nurses,midwives and technical staff who were posted in corona screening,ward,ICU or had given duty in the corona block of the hospitalwere included to participate in the study after informed consent. HCWs who were too sick or did not gave consent were excluded. 190 participants were enrolled.

- Data collection :A questionnaire was formed and distributed among the HCWs who had given their duties in corona block of the hospital and completed their quarantine.Participants were assured that the information collected would remain anonymous.The completed questionnaires were taken back for analysis.

- Data Management and Analyses:Fully completed questionnaires were extracted and exported to a Microsoft Excel 2016 for cleaning and coding. Numerical data was summarized as proportions.Tables were made and analysed.

\section{RESULTS:}

Out of the 190 participants studied, majority belonged to the age group of $30-40$ years $(51.1 \%)$, with a mean age of 26.1 years. Higher proportion were of males $(54.2 \%)$ than compared to females (45.8\%).Majority were married (61.6\%) and were living without family $(58.4 \%)$.In the block of the hospital which was designated for corona,majority were posted in wards $(61.6 \%)$,followed by OPD (21.6\%) and $16.8 \%$ were at ICU.Out of all the HCWs maximum were nursing staff (48.9\%),followed by doctors $(42.1 \%)$ and among them maximum had an experience of $2-5$ years (41.6\%). [Table 1]

Table l: Demographical Profile of Health Care Worker

\begin{tabular}{|l|l|l|}
\hline CHARACTERISTICS & NO & PERCENTAGE \\
\hline AGE (Mean \pm Sd) & $26.13 \pm 3.27$ & \\
\hline$<30$ year & 70 & 36.8 \\
\hline $30-40$ year & 97 & 51.1 \\
\hline$>40$ year & 23 & 12.1 \\
\hline GENDER & & \\
\hline MALE & 103 & 54.2 \\
\hline FEMALE & 87 & 45.8 \\
\hline MARITAL STATUS & 117 & 61.6 \\
\hline MARRIED & 73 & 38.4 \\
\hline UNMARRIED & \\
\hline LIVING WITH FAMILY & 41.6 \\
\hline YES & 79 & 58.4 \\
\hline NO & 111 & \\
\hline
\end{tabular}




\begin{tabular}{|c|c|c|}
\hline \multicolumn{3}{|l|}{ AREA OF DUTY } \\
\hline ICU & 32 & 16.8 \\
\hline WARD & 117 & 61.6 \\
\hline OPD & 41 & 21.6 \\
\hline \multicolumn{3}{|l|}{ DESIGNATION } \\
\hline Intern student & 10 & 5.3 \\
\hline Doctor & 80 & 42.1 \\
\hline Nursing Staff & 93 & 48.9 \\
\hline Technician & 7 & 3.7 \\
\hline \multicolumn{3}{|c|}{ YEAR OF EXPERIENCE } \\
\hline less than 2 years & 38 & 20.0 \\
\hline $2-5$ Year & 79 & 41.6 \\
\hline more than 5 years & 73 & 38.4 \\
\hline
\end{tabular}

The participants were scored on the basis of their replies.Maximum of them had an average knowledge $(47.9 \%)$, positive attitude $(57.4 \%)$ and good practice (51.1\%).[Table 2]

The factors associated with knowledge were age(best among the age group 30-40 years), working place(best in those posted at wards) and that too among nursing staff and years of working experience (maximum in those with an experience of 2-5 years).The groups which scored maximum in regards of positive attitude and good practice were those of age 30-40 years, posted at wards,majority of nurses and with working experience of more than 5 years. Apart from this, in the age group of less than 30 years majority had average knowledge, negative attitude and bad practice; in age group $30-40$ years majority had average knowledge, positive attitude and good practice; and in age group more than 40 years majority had poor knowledge, negative attitude and bad practice.In terms of working place,majority of those working in ICU had good knowledge, positive attitude and good practice; those in ward had average knowledge, negative attitude and good practice ; and majority ofthose in OPD had average knowledge, positive attitude and bad practice. Maximum of interns had poor knowledge, negative attitude and bad practice;doctors had average knowledge, positive attitude and good practice;nursing staff had equal number of participants with average and good knowledge, and majority had positive attitude and bad practice; technicians had good knowledge, negative attitude and bad practice. And maximum of those working for less than 2 years had good knowledge, positive attitude and bad practice; those with working experience of 2 to 5 years had good knowledge, positive attitude and good practice and those with working experience of more than 5 years had average knowledge, positive attitude and good practice. [Table 3]

Attitude, Practices

\begin{tabular}{|l|l|l|}
\hline SCORE & No of respondents & Percentage \\
\hline KNOWLEDGE & 17.9 \\
\hline POOR $(<60)$ & 34 & 47.9 \\
\hline AVERAGE $(60-75)$ & 91 & 34.2 \\
\hline GOOD $(>75)$ & 65 & 42.6 \\
\hline ATTITUDE & 57.4 \\
\hline NEGATIVE $(<60)$ & 81 & 48.9 \\
\hline POSITIVE $(>60)$ & 109 & \\
\hline PRACTICES & 93 & \\
\hline BAD &
\end{tabular}

Table 3:Factors influencing knowledge, attitude and practice

\begin{tabular}{|c|c|c|c|c|c|c|c|c|}
\hline \multirow{4}{*}{ VARIABLES } & \multicolumn{3}{|c|}{ KNOWLEDGE } & \multicolumn{2}{|l|}{ ATTITUDE } & \multicolumn{2}{|c|}{ PRACTICES } & \multirow{4}{*}{ Total } \\
\hline & \multirow{2}{*}{$\begin{array}{l}\text { POOR } \\
(n=34)\end{array}$} & \multirow{2}{*}{\begin{tabular}{|l} 
AVERAGE \\
$(n=91)$ \\
\end{tabular}} & \multirow{2}{*}{\begin{tabular}{|l|} 
GOOD \\
$(n=65)$ \\
\end{tabular}} & \multirow{2}{*}{$\begin{array}{l}\text { NEGATIVE } \\
(\mathrm{n}=81) \\
\end{array}$} & \multirow{2}{*}{\begin{tabular}{|l} 
POSITIVE \\
$(\mathrm{n}=109)$ \\
\end{tabular}} & \multirow{2}{*}{$\begin{array}{l}\text { BAD } \\
(n=93) \\
\end{array}$} & \multirow{2}{*}{$\begin{array}{l}\text { GOOD } \\
(n=97) \\
\end{array}$} & \\
\hline & & & & & & & & \\
\hline & $\mathrm{N}(\%)$ & $\mathrm{N}(\%)$ & $\mathrm{N}(\%)$ & $\mathrm{N}(\%)$ & $\mathrm{N}(\%)$ & $\mathrm{N}(\%)$ & $\mathrm{N}(\%)$ & \\
\hline \multicolumn{9}{|l|}{ AGE GROUP } \\
\hline$<30$ year & $14(20)$ & $33(47.1)$ & $23(32.8)$ & $41(58.5)$ & $29(41.4)$ & $37(52.8)$ & $33(47.1)$ & $70(36.8)$ \\
\hline $30-40$ year & 9(9.27) & $49(50.5)$ & $39(40.2)$ & $27(27.8)$ & $70(72.1)$ & $41(42.2)$ & $56(57.7)$ & 97(51.1) \\
\hline$>40$ year & $11(47.8)$ & $9(39.1)$ & $3(13)$ & $14(60.8)$ & $9(39.1)$ & $13(56.5)$ & $10(43.4)$ & $23(12.1)$ \\
\hline \multicolumn{9}{|c|}{ WORKING PLACE } \\
\hline ICU & $5(15.6)$ & $13(40.6)$ & $14(43.7)$ & $6(18.7)$ & 26(81.2) & $4(12.5)$ & $28(87.5)$ & $32(16.8)$ \\
\hline WARD & 19(16.2) & $62(52.9)$ & $36(30.7)$ & $63(53.8)$ & $54(46.1)$ & $55(47)$ & $62(52.9)$ & $117(61.6)$ \\
\hline OPD & $10(24.3)$ & $16(39)$ & $15(36.5)$ & $18(43.9)$ & $23(56)$ & $32(78)$ & $9(21.9)$ & $41(21.6)$ \\
\hline \multicolumn{9}{|c|}{ DESIGNATION } \\
\hline \begin{tabular}{|l|} 
Intern \\
student
\end{tabular} & $4(40)$ & $3(30)$ & $3(30)$ & $7(70)$ & $3(30)$ & $6(60)$ & $4(40)$ & $10(5.3)$ \\
\hline Doctor & $17(21.2)$ & $46(57.5)$ & $17(21.2)$ & $31(38.7)$ & $49(61.2)$ & $39(48.7)$ & $41(51.2)$ & $80(42.1)$ \\
\hline Nursing Staff & $11(11.8)$ & $41(44)$ & $41(44)$ & $39(90.6)$ & $54(58)$ & $48(51.6)$ & $45(48.3)$ & $93(48.1)$ \\
\hline Technician & $2(28.5)$ & $1(14.2)$ & $4(57.1)$ & $4(57.1)$ & $3(42.8)$ & $5(71.4)$ & $2(28.5)$ & $7(3.7)$ \\
\hline \multicolumn{9}{|c|}{ WORKING EXPERIENCE } \\
\hline \begin{tabular}{|l|} 
less than 2 \\
years
\end{tabular} & $9(23.6)$ & $14(36.8)$ & $15(39.4)$ & $17(44.7)$ & $21(55.2)$ & $27(71)$ & $11(28.9)$ & $38(20)$ \\
\hline 2-5 Year & $151(18.9)$ & $22(27.8)$ & $42(53.1)$ & $38(48.1)$ & $41(51.8)$ & $35(44.3)$ & $44(55.6)$ & $79(41.6)$ \\
\hline \begin{tabular}{|l} 
more than 5 \\
years
\end{tabular} & $10(13.6)$ & $55(75.3)$ & $8(10.9)$ & $26(35.6)$ & $47(64.3)$ & $24(32.8)$ & $49(67.1)$ & $73(38.4)$ \\
\hline
\end{tabular}

\section{CONCLUSION:}

The majority of the health care workers had an average knowledge,positive attitude and good practice which further varied according to their age, years of experience, designation and their posting place. Thus continued professional education and campaigns are suggested for the health care professionals.

\section{DISCUSSION:}

HCWs are not only at the forefront of the fight against this highly contagious infectious disease but are also directly or indirectly affected by it and the likelihood of acquiring this disease is higher among HCWs compared to the general population. It is therefore of paramount importance that HCWs across the world have adequate knowledge about all aspects of the disease from clinical manifestation, diagnosis, proposed treatment, and established prevention strategies.

As compared to a study conducted in Uganda in which $82.4 \%$ had good knowledge, our study showed a much lower score of $34.2 \%$ of good knowledge.The maximum participants in our study had average knowledge of $47.9 \%$. 
Similar to the study conducted in Uganda ${ }^{4}$, majority of our study participants also had a positive attitude (57.4\%).

Also in contrast to our study, a study conducted in Ho Chi Minh ${ }^{1}$ city of China showed very high level of knowledge (99.1\%) and attitude (97.9\%).

As per practice, our study showed a minute difference between those with good practice (51.1\%) and bad practice $(48.9 \%)$ as compared to the study conducted in Uganda ${ }^{4}$ where those with good practice where much higher than those with bad one.

Further education andtraining through continuous professional education and journalclubs, particularly on symptoms and transmission are essentialin improving the knowledge of HCW about COVID-19 inour setting. Continued professional education isadvised among HCWs in Uganda to improve knowledge of HCWs hence averting negative attitudes and promoting positive preventive and therapeutic practices. We recommend follow up studies involving teaching and non-teaching hospitals across the country.

\section{REFERENCES:}

1. Giao, Huynh, Nguyen \&Thi, Ngoc \&Thi Ngoc Han, Nguyen \&Khanh, Tran \&Ngan, Vo \& Tam, Vo \& Le An, Pham. (2020). Knowledge and attitude toward COVID-19 among healthcare workers at District 2 Hospital, Ho Chi Minh City. Asian Pacific Journal of Tropical Medicine. 13. 10.4103/1995-7645.280396.

2. WHO.Clinical management of severe acute respiratory infection (SARI) when COVID-19 disease is suspected available on http:// www. who.int/ publications-detail/clinical-management-of severe acute respiratory infection when novel coronavirus infection is suspected

3. Joint statement of IPHA,IAPSM for containment plan. Published on April 11 2020. Available at: https://www.iphaonline.org/wp-content/uploads/2020/ 04/Joint-Statement-of-IPHA IAPSM-for-COVID-19-containment-plan April11 6-pm Final-1.pdf

4. Olum R, Chekwech G, Wekha G, Nassozi DR and Bongomin F (2020) Coronavirus Disease-2019:Knowledge, Attitude, and Practices of Health Care Workers at Makerere University Teaching Hospitals,Uganda. Front. Public Health 8:181.doi: 10.3389/fpubh.2020.00181

5. World Health Organisation.Coronavirus disease(COVID-19). Advice for the public(2020). Available at: www.who.int/emergencies/disease/novelcoronavirus-2019/advice-for-public 